\title{
On the Poggendorff illusion: A note to Cumming's criticism of Chung Chiang's theory
}

\section{MARIO FARNE' 1 \\ UNIVERSITA DI BOLOGNA}

Cumming (1968), in his criticism of the theory formulated by Chung Chiang (1968), publishes a figure in which it is demonstrated that the Poggendorff illusion occurs even when the oblique and the vertical lines do not intersect but have a very narrow space between them. In this connection, it is interesting to remember that we can still obtain various kinds of geometrical illusions although the illusion-producing pattern is formed by subjective lines and contours [i.e., stimuli clearly perceived by the Ss but physically absent in the field (Schumann, 1904)].2 Figure la illustrates a case of the Poggendorff illusion in which the two parallel lines are replaced by subjective contours (note the appearance of a vertical white strip superimposed on black and gray rectangles; its outline may be seen even though there are no physical contours): the displacement effect, however, is evident all the same (Famé, 1968). The oblique line on the right is the continuation of the upper line on the left and not of the lower one, as gencrally seems the case.

In addition to that, Wund (1893) pointed out that the same result is noticed without any parallel lines at all, provided the two illusion-suffering segments are

slanted at an angle (Fig. 1b). In this case, the phenomenon may be weaker than in the usual condition and, furthermore, Sanford (1898) relates that according to some Ss it is also seen in the opposite direction; if, on the other hand, this figure is presented tachistoscopically (e.g., for $200 \mathrm{msec}$ ) the displacement appears in the well-known direction and strikingly so.

These observations, with those made by Cumming (1968), should be kept in mind for a further examination of Chung

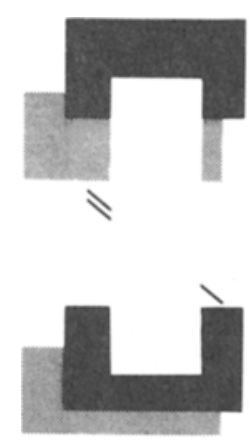

Chiang's theory (1968) invoking diffraction in the eye to explain the Poggendorff illusion.

\section{REFERENCES}

CHUNG CHIANG. A new theory to explain geometrical illusions produced by crossing lines. Perception \& Psychophysics, 1968, 3, 174-176.

CUMMING, G. D. A criticism of the diffraction theory of some geometrical illusions. Perception \& Psychophysics, 1968, 4, 375-376.

FARNE, M. Alcune osservazioni con linee virtuali e margini quasi percettivi. Bollettino della Societa I taliana di Biologia Sperimentale, 1968. 44, 1613-1616.

SANFORD, E. C. A course in experimental psychology. Boston: Heath, 1898.

SCHUMANN, F. Einige Beobachtungen über die Zusammenfassung von Gesichtscindrucken zu Einheiten. Psychologische Studien, 1904, 1. 1-32.

WUNDT, w. Grundzuge der physiologischen Psychologie. Leipzig: Engelmann, 1893.

\section{NOTES}

1. Address: Istituto di Psicologia, Università di Bologna, Bologna, Italy.

2. Incidentally, it is possible to obtain visual aftereffects as well using subjective lines and contours as inspection stimuli (Farnè, 1968).

Figure 1. 